\title{
The Forms and Functions of Impulsive Actions: Implications for Behavioral Assessment and Therapy
}

\author{
Richard F. Farmer and Jeannie A. Golden
}

\begin{abstract}
Impulsivity is a central defining feature of several psychiatric disorders and a frequent correlate of many forms of psychopathology and maladjustment. Despite recognition of the importance of impulsivity to an understanding of a wide variety of clinically-relevant behaviors, this multifaceted construct remains ill-defined and not well understood. The primary aims of this article are to briefly summarize theory and basic research on impulsivity from personality theory, and to propose a behavioral framework for conceptualizing factors that contribute to and maintain behaviors often labeled as impulsive. Behavioral interventions potentially useful for addressing impulsive behavior outlined within this framework are briefly described.
\end{abstract}

Keywords : Impulsivity, psychiatric disorders, clinical applications, functional assessment, behavioral intervention

Impulsivity is increasingly recognized as a clinically important feature of many psychiatric disorders and clinicalconcerns. Although widely regarded as a multifaceted construct, there is little consensus as how to best define impulsivity. As this review will highlight, the term impulsive behavior refers to a broad range of behavioral tendencies that is highly variable in both form (topography) and function. Following a review of theory and basic research on impulsivity, a behavioral framework for conceptualizing impulsive action is proposed. Within this framework, impulsive behaviors are categorized according to their associated functional properties or corresponding skills deficits. Behavioral interventions conceptually tied to these functional formulations of impulsivity are briefly highlighted.

\section{CONCEPTUALIZING THE DOMAIN OF IMPULSIVITY: SUGGESTIONS FROM PERSONALITY THEORY AND RESEARCH}

Impulsivity is not a unitary concept; rather, the label "impulsive" is often applied to a heterogeneous collection of behaviors that vary considerably in terms of form and function. Some conceptualizations of impulsivity, for example, emphasize the adaptive qualities associated with impulsive acts under some circumstances. Dickman (1990; Dickman \& Meyer, 1988), for instance, has highlighted a form of impulsivity that is characterized by actions performed with little forethought that result in positive or optimal outcomes (e.g., suddenly breaking and maneuvering a car in order to avoid an object on the road). The ability to respond quickly and skillfully with little deliberation can be adaptive or beneficial in such circumstances. Dickman contrasts this form of impulsivity with a more maladaptive or non-optimal form of impulsivity, whereby actions are frequently carried out with little planning or forethought and have a relatively high likelihood of producing inaccurate, non-optimal, harmful, or aversive outcomes (e.g., engagement in unplanned and risky sexual behavior while intoxicated with a previously unknown partner following a chance meeting).

Several different manifestations of impulsivity, both adaptive and maladaptive, have been described in the personality and clinical literatures (e.g., Barrett \& Stanford, 1996; Depue \& Collins, 1999; Evenden, 1999; Whiteside \& Lynam, 2001; Zuckerman, 1996), including: sensation seeking, risk taking, novelty seeking, thrill or excitement seeking, reward seeking, extraversion, venturesomeness, hyperactivity, response perseveration, and need for immediate gratification. Other references to impulsive actions suggest the absence of a skill or some other type of deficit: disinhibition, low deliberation/premeditation, deficit response reflection, impatience, low persistence, non-planning, low future orientation, low harm avoidance, low anxiety, poor inhibitory control, poor fear conditioning, low self-control, poor self-regulation, impaired capacity for delay, inability to delay gratification, inability to 
refrain from acting on urges or impulses, and low persistence. Finally, conceptualizations of impulsivity have also included forms of behavior that are occasioned by other factors, such as urgency for action under conditions of negative affect (Wallace, Bachorowski, \& Newman, 1991; Whiteside \& Lynam, 2001).

These various forms of impulsivity are distinct in terms of topography, function, and associated behavioral skills and their inclusion under the same construct label masks important distinctions in their functions and associated predisposing factors. As will be reviewed shortly, sensation seeking and risk taking are examples of actions that might be primarily maintained by positive reinforcement processes that accompany such behaviors. Conversely, fearlessness or disinhibition might denote behavioral tendencies that appear impulsive on the surface, but that actually refer to a general non-reactivity to aversive stimuli or punishment cues that would otherwise inhibit behavior. Alternatively, impulsive behavior under conditions of negative affect might be maintained by the automatic negative reinforcement processes associated with such behavior (e.g., relief from unpleasant emotional states; see Miltenberger, 2005). Similarly, skill deficits that limit behavioral options might account for some behaviors that appear erratic or impulsive.

To date, personality theorists and researchers have contributed the most to the literature on impulsivity. A brief review of major perspectives of impulsivity from personality theory follows. In subsequent sections, the theories and observations from personality psychology are translated into a behavioral framework for conceptualizing the varieties of impulsive action and accompanied by suggestions for behaviorally-based interventions that are functionally rela ted to these conceptualizations.

\section{Personality Theory Perspectives on Impulsivity}

In this section, two productive lines of research on impulsivity are briefly summarized. First to be reviewed is Gray's multi-level motivational and neuropsychological theoretical model of impulsivity. Gray's original reinforcement sensitivity theory (Gray, 1973, 1987) has been incorporated into other major models of personality and psychopathology, such as those proposed by Cloninger (1987), Newman (1987), and Fowles (1980). This theoretical model has undergone extensive revision within the last decade (Corr, 2008; Gray \& McNaughton, 2000; Smillie, Pickering, \& Jackson, 2006), and it is this revised model that is summarized below. This presentation is followed by a brief review of the five-factor model (FFM) of personality, and how impulsivity has been conceptualized within this well-researched and validated framework.

\section{Gray's Reinforcement Sensitivity Theory}

A central assumption of Gray's model is that higher-order personality traits such as anxiety and impulsivity arise from neurologically-based motivational systems. In descriptions of the reinforcement sensitivity theory (RST) model, terms such as "reward" and "punishment" are conflations of antecedent and consequent events, their associated emotional/motivational valence, and the behaviors related to these events (for an illustration, see Gray \& McNaughton, 2000, pp. 48-52). Rewards, for example, are regarded as positive incentive stimuli that are associated with positive affect and, correspondingly, a positive incentive motivation to approach such stimuli. In humans, examples of incentive emotional states that facilitate approach behavior to reward cues include attraction, desire, elation, enthusiasm, excitement, expectation, and hope. Consequently, the terms "reward" and "punishment" as used in this section are not isomorphic with the operant terms "reinforcer" and "punisher," with these latter concepts defined primarily by the effects that consequences have on behavior (either to increase or decrease the frequency, intensity, or duration of behavior, respectively).

In Gray's model (Gray, 1987; Gray \& McNaughton, 2000), there are three conceptual biobehavioral systems: a threat-reactivity system (i.e., the fight/flight/freezing system, or FFFS), a 
reward-reactivity system (i.e., the Behavioral Activation System, or BAS), and a conflict-reactivity system (i.e., the Behavioral Inhibition System, or BIS). In the revised theoretical model, the FFFS is thought to mediate reactivity to all aversive stimuli, including conditioned and unconditioned punishment cues (some of these functions were attributed to the BIS in earlier iterations of this model). Fear and panic are the common emotional expressions derived from this system, and active avoidance, escape and defensive behaviors are the primary associated action tendencies. Conversely, the BAS concept is used to account for trait impulsivity and individual differences in reactivity to all forms of appetitive stimuli. BAS activation is associated with approach behavior and behavioral activation, positive moods in the presence of reward cues, and reactivity to the termination or omission of aversive environmental events. The BIS is activated by sources that generate response conflict (i.e., FFFS and BAS coactivation), and hypothesized to give rise to trait anxiety primarily in situations associated with competing motivations or goals (e.g., those associated with conflict, ambiguity, or uncertainty). BIS activation, in turn, results in the initial inhibition of ongoing behavior and increases in the allocation of attentional resources to cues associated with conflict (e.g., in the service of risk assessment). Conflict resolution, in turn, is resolved through either FFFS (e.g., avoid, escape) or BAS (e.g., approach) engagement.

Within Gray's model, reward-seeking behaviors are primarily mediated by BAS activation. Behaviors that fall under the headings of novelty seeking, risk taking, or sensation seeking are examples of action tendencies thought to be primarily associated with BAS mediation (Simillie et al., 2006). Disinhibited behavior, in contrast, might occur in the absence of endogenous regulatory mechanisms that function to inhibit behavior in the presence of threat, danger, or punishment cues, or in situations where response conflicts might be present. Some theorists, for example, have historically associated disinhibition with fearlessness (e.g., Lykken 1957). In Gray's revised model, fearlessness would be primarily associated with the relatively weak activation of the FFFS in situations where threat-, danger-, or punishment-related cues are present. In the relative absence of the experience of fear (and FFFS activation), BIS activation would also be unlikely, as BIS activation depends on the coactivation of both FFFS and BAS systems.

In most situations, however, impulsivity (or disinhibition) involves the reactivity and functional outcomes associated with all three conceptual systems in the revised RST (Simillie et al., 2006). Behavior frequently occurs in environments that include mixed incentives (both rewards and punishers) for behavior, and hence offer a degree of conflict depending on the strength or reactivity of each of the three systems. Passive avoidance is one example of a process that likely involves all three systems (Smillie et al., 2006). Passive avoidance learning refers to the learned inhibition of behavior in order to avoid punishment, and a passive avoidance error is an instance where a person fails to inhibit responding to punishment cues. Ongoing behavior is, by definition, behavior that has historically been maintained by reactivity to rewards (BAS activation). When threat or punishment signals are introduced (FFFS activation) during ongoing behavior, a conflict situation ensures (BIS activation), resulting in the inhibition of behavior while additional information is gathered and processed. This additional information, in turn, helps to clarify the nature of this conflict and suggests appropriate forms of behavioral resolution (e.g., active avoidance or escape, continued inhibition of behavior, the resumption of behavior).

\section{Five Factor Model Perspectives on Impulsivity}

Researchers interested in the "structure of personality" have frequently relied on exploratory factor analytic (EFA) methods for identifying patterns of covariation among behavioral tendencies, including typical emotional experiences, frequently held attitudes, and preferences. EFA statistical methods have had a central role in the development and evaluation of the five-factor model (FFM) of personality, and researchers in this area (e.g., Costa \& McCrae, 1992; Goldberg, 1990) are in general agreement as to the make-up of the five superordinate personality domains: extraversion, agreeableness, 
conscientiousness, neuroticism (versus emotional stability), and openness to experience (or, alternatively, intellect/imagination/culture).

Although FFM researchers often utilize the same research methods for studying behavior covariation (i.e., multivariate correlational techniques as applied to self-reports of emotion, experience, and behavior), they often differ on ideas concerning the source or cause of this covariation. McCrae (2004, p. 3), for example, has proposed a strong trait view, whereby FFM personality dimensions are regarded as "biologically based characteristics of the human species" that are not further modified by environmental or cultural factors. Other FFM researchers have to varying degrees integrated some form of environmental influence into their models.

Within Costa and McCrae's (1992) descriptive FFM framework, Whiteside and Lynam (2001) identified four facet-level impulsivity-related personality traits extracted from three-higher-order domains. These higher-order domains (and associated facets) are: extraversion (sensation seeking), and neuroticism (urgency of action in the presence of negative affect), and low conscientiousness (low premeditation and low perseverance). Apart from extraversion and neuroticism, other FFM personality domains have not been systematically integrated into Gray's RST or other biologically informed theories of impulsivity, even though low conscientiousness is frequently associated with impulsive behaviors (Depue \& Collins, 1999; Whiteside \& Lynam, 2001). This might be due to the observation that, unlike anxiety and impulsivity (or neuroticism and extraversion), conscientiousness lacks accompanying emotional content and, correspondingly, an associated emotional/motivational biological system (Depue \& Collins, 1999). In relation to impulsivity, conscientiousness might instead be strongly tied to a future orientation, a tendency to engage in rule-following, or an ability delay of gratification in the service of more distal and highly valued rewards.

\section{Multiple Influences Associated with Impulsive Acts}

Mounting evidence suggests that, rather than a result of a single biological substrate, behavioral tendencies generally described as impulsive are associated with independent processes and interactions linked to several neurobiological systems (Depue \& Collins, 1999; Evenden, 1999). This is also thought to be true of processes associated with behavioral disinhibition (e.g., Nigg, 2000), which appears to be largely independent of trait impulsivity (Gray, 1987). Problems associated with frequent impulsive acts might therefore be the result of several different processes that combine or interact. Young et al. (2009), for example, has reported that conduct problems among youth are associated with motivational problems such as high risk taking (associated with reward seeking) and low fear of punishment.

\section{VIEWS ON IMPULSIVITY FROM A BEHAVIORAL PERSPECTIVE: BEHAVIOR FORMULATION AND THERAPY IMPLICATIONS}

Personality constructs and diagnostic categories are usually defined by specific forms of behavior, or behavior topography, which is assumed to demonstrate some degree of temporal and crosssituational consistency. From the preceding review, it would appear that the same construct label ("impulsivity") is often applied to a wide range of behavioral phenomena that differ substantially not only in form, but also in function and presumed psychobiological substrates. Impulsivity as a concept, one might suggest, currently has little cohesiveness and, consequently, limited scientific value.

In this section, the varieties of impulsivity described in the preceding review and in other sources are reframed from a behavioral perspective. Traditionally, behavioral assessment has been primarily concerned with functions (i.e., outcomes produced by behavior that affect its future probability) rather than forms (i.e., surface-level or descriptive features or topography) of specific behaviors (Nelson-Gray \& Farmer, 1999). While still emphasizing these functions, behavioral assessors in recent years have focused their attention on broader classes of behavior. Among these are functional response domains, or groups of behavior that are similar in terms of the outcomes they produce even though the behaviors 
themselves might be very different in form or topography (Farmer \& Nelson-Gray, 2005; Follette, Naugle, \& Linnerooth, 2000; Malott, Malott, \& Trojan, 2000). Correspondingly, the behavioral framework elaborated below and summarized in Table 1 emphasizes the functions of ongoing behavior, with comparatively less emphasis placed on the forms of behavior in the conceptualization of impulsivity. Behavioral interventions closely tied to these functional formulations are also briefly described.

Table 1: Impulsive Behaviors Categorized by Functional Response Domain

\begin{tabular}{|c|c|c|}
\hline $\begin{array}{l}\text { Functional Response } \\
\text { Domain }\end{array}$ & $\begin{array}{l}\text { Primary Functional Property } \\
\text { of Behavior }\end{array}$ & $\begin{array}{c}\text { Examples of Therapeutic Techniques or } \\
\text { Interventions }\end{array}$ \\
\hline $\begin{array}{l}\text { Excessive appetitive } \\
\text { behavior }\end{array}$ & $\begin{array}{c}\text { Produce positive reinforcing } \\
\text { consequences, particularly } \\
\text { those that are socially- } \\
\text { mediated }\end{array}$ & $\begin{array}{l}\text { Remove positive reinforcers associated with } \\
\text { excessive behavior (e.g., attention); } \\
\text { contingency management procedures; covert } \\
\text { sensitization, cue elimination; skill train ing } \\
\text { (e.g., assertiveness). }\end{array}$ \\
\hline $\begin{array}{l}\text { Behavior ineffectively } \\
\text { controlled }\end{array}$ & $\begin{array}{l}\text { Behavior not influenced by } \\
\text { the consequences that it } \\
\text { produces }\end{array}$ & $\begin{array}{l}\text { Skills training (e.g., response } \\
\text { reflection skills); functional/chain } \\
\text { analyses of behavior; problem solving. }\end{array}$ \\
\hline Experiential avoidance & $\begin{array}{c}\text { Produce negative reinforcing } \\
\text { consequences (e.g., relief } \\
\text { from aversive private } \\
\text { events). }\end{array}$ & $\begin{array}{l}\text { Reduce/eliminate establishing operations that } \\
\text { occasion avoidance behavior; "urge surfing"; } \\
\text { exposure-based therapies; skill training. }\end{array}$ \\
\hline Deficits in rule control & $\begin{array}{l}\text { Behavior is largely in } \\
\text { response to immediate } \\
\text { contingencies; little } \\
\text { influence of rules, goals, } \\
\text { values, and standards on } \\
\text { behavior. }\end{array}$ & $\begin{array}{l}\text { Motivational interviewing; "acting toward a } \\
\text { goal"; "committed" action"; functional/chain } \\
\text { analyses of target behaviors }\end{array}$ \\
\hline Poor inhibitory skills & $\begin{array}{l}\text { Non-reactivity to cues that } \\
\text { would otherwise inhibit } \\
\text { behavior. }\end{array}$ & Stimulus control techniques; cue exposure. \\
\hline $\begin{array}{c}\text { Poor stimulus } \\
\text { discrimination/ } \\
\text { inappropriate stimulus } \\
\text { control }\end{array}$ & $\begin{array}{l}\text { Behavior is inappropriate for } \\
\text { contexts where it is } \\
\text { displayed. }\end{array}$ & $\begin{array}{l}\text { Discrimination training; stimulus control } \\
\text { techniques; mindfulness interventions; self- } \\
\text { labeling training }\end{array}$ \\
\hline $\begin{array}{l}\text { Inability to cope with } \\
\text { delay }\end{array}$ & $\begin{array}{l}\text { Selection of less favorable } \\
\text { immediate consequences } \\
\text { rather than more favorable } \\
\text { delayed consequences. }\end{array}$ & $\begin{array}{l}\text { Contingency management; self- } \\
\text { management techniques; skill } \\
\text { training. }\end{array}$ \\
\hline
\end{tabular}

The Varieties of and Functions Associated with Impulsive Actions

The preceding review of personality perspectives on impulsivity proposes that individual differences in reactivity to diverse environmental events and behavioral consequences are linked to biological predispositions. What might constitute these underlying predispositions, however, is still a matter of considerable debate. In this section, emphasis is instead placed on the outlines of a framework of impulsive behavior distinguished in terms of reactivity to immediate environmental cues or circumstances (e.g., cues that signal reward or punishment), the extent to which is behavior is under the influence of rules (or rule-governed), as well as any skills deficits that might limit the range of behavioral options available for responding. The framework presented here is not necessarily in conflict with models that emphasize underlying biological processes (e.g., genetics, neurochemical functions, temperament), 
but is instead complementary and extends existing accounts of impulsive behavior by incorporating environmental determinants of actions, including learning history.

\section{Impulsivity as an Excessive Appetitive Behavior}

As the above review of personality theories suggests, some forms of impulsivity have been associated with increased activity of endogenous reward centers and heightened reactivity to conditioned and unconditioned stimuli associated with reward. Although debate continues as to what personality dimensions most strongly reflect these tendencies, current views emphasize either the superordinate personality domain of extraversion or Gray's impulsivity dimension (which can also be defined as bisecting Hans Eysenck's orthogonal domains of extraversion and neuroticism in factor space; see Gray, 1987). Some have referred to this variant of impulsivity as "reward drive" or "reward reactivity" in order to distinguish this potentially adaptive form of impulsivity from a more malignant variant (termed "rash impulsivity," as described in the following section; see also Dawe, Gullo, \& Loxton, 2004 and Simillie et al., 2006).

With reference to Gray's model, impulsive behavioral tendencies subsumed under this heading would be those linked to BAS-related activation, namely approach behavior in the presence of positive affect or reward cues. Examples of such behavior might include those tied to social affiliation, talkativeness, assertiveness, energy and activity levels, vigorousness, boldness, and daring (Goldberg, 1992).

Appetitive behavior can become problematic, particularly if carried out in excess or if harmful or maladaptive consequences are probable. Behavioral excesses are often maintained by the reinforcing properties associated with attention or approval, particularly among children (Scotti, Morris, McNeil, \& Hawkins, 1996). Among adults, some disorders are defined, in part, by attention-seeking behavior or by actions whereby others are used or exploited for one's personal benefit. Included among these are the erratic-emotiona-dramatic personality disorders (i.e., histrionic, narcissistic, borderline, antisocial). When anticipated reinforcers from others are not forthcoming, behavior might shift to something more coercive or hostile (not unlike an extinction burst). Such coercive behavior might be instrumental in terminating aversive aspects of another's behavior (e.g., opposition) or to get others to comply with one's demands (Patterson \& Hops, 1972). Interventions that block, reduce, or alter coercive control, such as assertiveness or communication training, might be helpful in such instances.

For impulsive behaviors that are appetitive in nature, a variety of behavioral interventions might be considered. Contingency management procedures, for example, involve the delivery of rewards or incentives for positive or desirable behaviors and the withholding or removal of rewards or incentives for undesirable or problematic behavior, and are best suited for behaviors that are primarily maintained by immediate consequences (Boyce \& Roman, 2003). A first step in implementing such procedures is the identification of the reinforcers that maintain problematic behavior (e.g., attention, access to tangible rewards). Once identified, reinforcers that support problematic behavior might be removed and reinforcers for desirable behavior either introduced or strengthened.

Covert sensitization procedures are sometimes helpful for behavioral excesses maintained by positive reinforcers that are otherwise difficult to remove or influence. This approach has been associated with the reduction in or elimination of a variety of problematic behaviors traditionally associated with impulsivity, such as substance abuse, overeating, gambling, exhibitionism, and nail biting (Kearney, 2006). When covert sensitization procedures are used, the client is initially instructed to imagine him- or herself participating in the problematic behavior in a usual environment. Reinforcers that might follow such behavior in natural environments, however, are omitted from imagined scenarios. Rather, once engagement in the target behavior is initiated and clearly visualized, the therapist instructs the client to imagine an aversive event that occurs concurrently with the behavior, such as becoming nauseous to the point of vomiting or experiencing ridicule from others. These negative consequences, in turn, are 
attenuated when the client subsequently imagines him or herself stopping the behavior and leaving the situation (with the cessation of behavior and escape from the situation also associated with a sense of relief). Such pairings of the problem behavior with an aversive consequence is repeated several times during future therapy sessions (e.g., about 5 to 10 imagined scenes per session over 30 sessions).

In situ training has shown some effectiveness with very young children in the generalization of safety skills (resisting the temptation to play with firearms in unsupervised situations). This procedure involves "catching" the child approaching or touching the forbidden object in the generalization setting, followed by role-play, differential reinforcement, corrective feedback and rehearsal (Kelso, Miltenberger, Watres, Emgemo-Helm, \& Bagne, 2007; Miltenberger et al., 2009). Similarly, adolescents with serious emotional disturbances have been taught self-management skills that enable them to exhibit on-task and socially appropriate behavior without adult supervision, with some indication that these learned behaviors are maintained over time and generalize to relevant settings (Ninness, Fuerst, Rutherford, \& Glenn, 1991). In cases of impulsivity that involve the exhibition of undesirable behaviors in unsupervised situations, it may be helpful to teach self-management procedure followed by training in generalization settings.

Finally, cue elimination procedures or other stimulus control techniques might be considered. With cue elimination, cues that signal the availability of rewards for problematic behavior are removed. In the case of impulsive over-eating or alcohol misuse, cues that make these behaviors more likely (e.g., sight of snack foods or wine bottle on the kitchen counter) might be eliminated or removed from view, thus reducing the number of contexts associated with temptation. Similarly, among teenagers, the presence of certain peers often occasions delinquent behavior. As a result, some therapists recommend changes in peer groups as a way to reduce disruptive behavior problems (Poling \& Gaynor, 2003).

\section{Behavior Ineffectively Controlled (or "Rash Impulsivity”)}

A characteristic of this response class is that the consequences of behavior are not sufficient enough to affect its future probability. The concept of rash impulsivity is included within this functional domain because behaviors subsumed under this category are often personally harmful, aversive to others, or generally dysfunctional given the context within which they occur. In the personality literature, there is also a suggestion that this form of impulsivity is associated with a weak tendency to approach reward cues or avoid punishment cues (Smillie \& Jackson, 2006). That is, rash impulsivity might be characterized by a general non-reactivity to cues that signal reward or punishment for behavior.

Conduct disorder (CD), antisocial personality disorder (ASPD), and early onset substance abuse disorders (SUDS) have been associated with impulsive tendencies consistent with this general type of impulsivity (Dawe et al., 2004; Moeller, Barratt, Dougherty, Schmitz, \& Swann, 2001). These disorders plus attention deficit/hyperactivity disorder (ADHD) and oppositional defiant disorder (ODD) demonstrate lifetime comorbidity rates that are substantially greater than chance, with these disorders frequently subsumed under the general heading of externalizing disorders (Farmer, Seeley, Kosty, \& Lewinsohn, in press; Krueger, 1999). CD/ASPD and early onset substance use disorders, in particular, demonstrate particularly strong associations with one another. ADHD and ODD are more modestly associated with these other disorders (Disney, Elkins, McGue, \& Iacono, 1999; Farmer et al., in press). Persons who have disorders from these categories have been shown in a variety of laboratory tasks to demonstrate impulsive response styles that are not optimal in relation to actual behavioral contingencies (e.g., Dawe et al., 2004; Farmer \& Rucklidge, 2006; Kirby, Petry, \& Bickel, 1999; Lykken, 1995), such as a greater tendency to emit behaviors that result in punishing or aversive outcomes.

What processes might be associated with a general non-reactivity to consequences? There are probably several, some of which are likely captured by other functional response domains described in this section. Because rash impulsivity as popularly described is characterized by a lack of deliberation, 
planning, or foresight, the primary problem here might be one in associating behavior with consequences. The ability to anticipate behavior-consequence relations is an important consideration in distinguishing adaptive from more maladaptive forms of impulsivity in some theoretical models (Dickman, 1990; Smillie \& Jackson, 2006). Laboratory research, for example, demonstrates that the amount of time spent viewing feedback on response-consequence associations (sometime termed "response reflectivity") is the single best predictor of effective versus impulsive responding (Farmer et al., 2003; Farmer, Whitehead, \& Woolcock, 2007). Additionally, when disinhibited participants are forced to view feedback on outcomes of their behavior during these tasks (or required to consider response-consequence relations), they behave in a less impulsive manner over time when compared to those who are not required to view such feedback (Patte rson \& Newman, 1993). An implication of this research is that impulsivity can be reduced and behavior can become more effective if persons simply stop to notice the effects of their behavior before resuming ongoing action.

When clients display minimal awareness of the consequences of their actions, this might be because they have not made behavior-consequence associations or because they have formed inaccurate verbal rule statements concerning relationships between behavior and outcomes. Experimental research indicates that when persons are unable to accurately describe behavior-consequence relations, behavior is rarely influenced by consequences (Spielberger \& DeNike, 1966). To facilitate recognition of these relations, interventions might involve some form of overt recitation of consequences that follow target behaviors, including both positive and negative outcomes as well as those that are immediate and delayed.

A core feature of some therapies for impulsive behavioral tendencies, such as dialectical behavior therapy (DBT; Linehan, 1993a), is the clinical functional analysis (sometimes also referred to as a behavioral chain analysis). There are at least three primary related goals associated with such analyses: (a) to identify the sequence of events that precede and follow problem behavior, (b) to highlight both the adaptive and maladaptive consequences that typically accompany such behavior, and (c) to inform the development of intervention strategies based on findings from the analysis, including the identification of alternative behaviors that are less harmful yet have some of the reinforcing properties of problematic behaviors targeted for elimination. In DBT, for example, functional analyses of problem behavior are often followed by "solution analyses," which is a general problem solving approach whereby clients are encouraged to generate behavioral solutions to the problems that occasioned self-harm behaviors. These possible solutions are then evaluated in terms of their likely outcomes. For the solution that has the greatest potential for producing desirable and non-harmful outcomes, a behavioral plan is generated for carrying out this alternative should antecedents associated with self-harm behavior again occur (e.g., as an alternative to cutting one's skin with a razor to produce a sense of relief, hold ice instead which does not result in tissue damage). Although problem-solving based on the functional qualities of self-injurious behavior is a central feature of DBT, and DBT has been found to be associated with greater reductions in self-injurious and suicidal behaviors compared to other therapies (e.g., Linehan, Armstrong, Suarez, Allmon, \& Heard, 1991; Linehan et al., 2006), problem-solving therapy as a stand alone treatment for non-suicidal self-injury has produced mixed results (Muehlenkamp, 2006).

\section{Impulsive Behavior in the Service of Providing Relief (or Experiential Avoidance)}

As a functional response class, experiential avoidance involves two components: an unwillingness to remain in contact with private events such as emotions, thoughts, or physiological sensations, and the taking of action to alter the frequency, intensity, or duration of these events or the contexts that occasion them (Hayes, Wilson, Gifford, Follette, \& Strosahl, 1996). Impulsivity associated with acute emotional distress is a feature of some personality models of impulsivity (e.g., Whiteside \& Lynam, 2001), and has been frequently described in the experimental and clinical literatures. Several experimental investigations into impulsivity or disinhibition, for example, have found evidence for “anxious impulsivity" (e.g., Farmer et al., 2007; Wallace et al., 1991). 
Non-suicidal self-injury is a common feature of some psychiatric disorders, including borderline personality disorder. Although the functions associated with such behavior are many, the relief that such behavior causes is often cited among the reasons for why some persons engage in intentional self-harm (Brown, Comtois, \& Linehan, 2002; Klonsky \& Olino, 2008). For those undergoing withdrawal associated with substance abuse, impulsive actions (e.g., related to getting drugs or the money to purchase drugs) might be committed in the service of providing relief from aversive withdrawal symptoms or strong urges to use. Among those who frequently binge eat, negative moods and food cravings associated with prolonged restricted food intake often occasion such episodes (Redlin, Miltenberger, Crosby, Wolff, \& Stickney, 2002; Stickney \& Miltenberger, 1999).

When events such as negative moods, withdrawal symptoms, or food deprivation increase the reinforcing properties associated with impulsive actions, they are likely acting as establishing operations. Establishing operations refer to the influence that events, operations, or conditions have on behavior by temporarily altering reinforcing or punishing properties of consequences (Michael, 1982; Miltenberger, 2005). For impulsive actions occasioned by such operations, interventions might emphasize the prevention or reduction of their occurrence. Examples include interventions for bulimia or binge eating disorder, several of which include treatment elements that emphasize the normalization of eating habits and behaviors. An aim of such an approach is to reduce binge-eating episodes by eliminating prolonged food deprivation that results in ravenous hunger. To the extent that intentional self-harm behaviors are occasioned by negative mood, interventions might be selected that reduce vulnerability to negative moods or involve the development of behavioral skills for coping with negative mood when present (Linehan, 1993b).

Among those with histories of abuse or neglect by others, interpersonal cues (e.g., facial expressions, voice intonation, verbal admonitions) can serve as discriminative stimuli that trigger negative emotional states (e.g., fear, anxiety, anger, guilt). Rather than tolerate these aversive emotional states, traumatized individuals might cope through dissociative processes (e.g., emotional numbing). Dissociative activities, by definition, are associated with disruptions or alterations in conscious experience, memory, and identity (American Psychiatric Association, 2000). Functionally, dissociative responding might have initially served as an adaptive coping response that lessened the psychological impact of a traumatic event or otherwise provided temporary relief. When used chronically and inflexibly over time, however, dissociation can become maladaptive.

As an example of experiential avoidance, dissociation allows persons to psychologically escape or avoid a situation or context. This escape or avoidance, in turn, reduces contact with current cues or events, including the natural consequences associated with behavior in such contexts. Individuals who respond with dissociation to stimuli that elicit emotional responses such as shame, for example, will be less likely to discover that these emotional responses will diminish or extinguish with time on their own, or that the situation might provide additional information that suggests such emotional reactions are unjustified. Similarly, dissociation can also disrupt the association that some behaviors have with reinforcing outcomes, thereby eliminating important information concerning the effectiveness of behavior (e.g., the act of telling the truth results in warm and trusting responses from others) (Foa \& Kozak, 1986). Therapeutically, exposure-based interventions (e.g., in vivo exposure, imaginal exposure) coupled with skills training might be used to replace dissociative activities as a form of coping (see Nemeroff, Bremner, Foa, Mayberg, North \& Stein, 2006, for a review of these procedures and their effectiveness).

A number of other behavioral intervention strategies are geared toward countering establishing operations that are associated with unpleasant states of emotional activation or arousal, or that produce a lessening of these states once present. These include training in skills that facilitate emotional relief. Examples include relaxation training, imagery techniques, breathing exercises, and meditation practices. Among other effects, techniques such as these can reduce unpleasant emotional experiences (anxiety, 
fear, anger, guilt) by producing a state of activation that is incompatible with these emotional states. Such techniques also facilitate a here-and-now focus, directing the focus of one's attentions and thoughts to the present moment and away from future concerns or recollections of distressing past events.

Alternatively, if impulsive actions represent a form of escape or avoidance behavior, and if such avoidance behavior is not justified or is excessive given the situation, various exposure-based interventions might be considered. A goal of such interventions is to reduce aversive emotional arousal and behavioral avoidance to events that do not represent an actual threat or danger. Examples of exposure interventions include in-vivo exposure, imaginal exposure, informal exposure, cue exposure and interoceptive exposure (Farmer \& Chapman, 2008).

Urge surfing is an example of a behavioral skill that can be used to facilitate tolerance of urgent action impulses without acting on them. Originally developed as an intervention for substance misuse (Lloyd, 2003; Marlatt \& Gordon, 1985), urge surfing is a skill that can be developed and strengthened with practice, and applied in situations where urges arise that usually precede harmful impulsive behaviors (e.g., substance misuse, binge eating, gambling, promiscuous sex). A core skill associated with urge surfing is the ability to observe within oneself the rise and fall of urges (much like ocean waves that gradually build, crest, and subside), and to "surf" or stay with these urges without acting on them.

Impulsivity as an Indicator of Strong Reactivity to Immediate Environmental Cues, Deficits in Rule Control, or Both

The behavior of some persons may appear to others to be strongly influenced by cues that signal immediate reinforcing consequences for behavior. Poor self-control is sometimes suggested when behavior is strongly influenced by immediate environmental rewards (Logue, 1995). When immediate environmental events exert a strong influence, and when there is an absence of rules for behavior, actions may appear to be random, erratic, stimulus driven, and variable across situational contexts, resulting in variable and ineffective responding (Barkley, 1997).

In behavioral descriptions of rule-governed behavior, a rule is a verbal description of a behavioral contingency that includes some combination of the following elements: (a) a particular form of behavior, (b) a consequence that the behavior will likely produce, and (c) an antecedent condition that, when present, signals that a given behavior will produce a specified consequence (Anderson, Hawkins, Freeman, \& Scotti, 2000). Rule-governed behavior describes a process whereby behaviors are influenced by verbal statements or rules that specify the contingencies for behavior (Malott, 1989). The rulegoverned behavior concept is frequently invoked to account for behavior that is influenced by delayed or distal consequences (Malott et al., 2000). From a personality perspective, broad personality traits such as conscientiousness (Cloninger, 1987; Costa \& McCrae, 1992; Goldberg, 1992) and traditionalism (Tellegen, 1999) are perhaps most strongly associated with the concept of rule-governed behavior.

For persons whose behavior appears to be excessively influenced by immediate events, a general treatment goal might be to facilitate a shift away from immediate contingency control to rule control. Doing so might result in behavior that is more "purposive" or goal-directed, and less influenced by immediate environmental events (and hence less impulsive). Relatedly, there is a suggestion that the tendency to stop and reflect on one's actions, particularly the consequences produced by them, may have an important role in the subsequent development of accurate rules for guiding behavior (Barkley, 1997). Consequently, interventions that increase the salience of consequences associated with behavior (e.g., chain analysis, mindfulness, response reflection, problem solving) might assist individuals in developing accurate rules for behavior by challenging the client to make explicit connections between actions and outcomes. 
Additionally, a number of values-based interventions have been developed and evaluated in recent years, not all of which are explicitly behavioral in nature. Motivational interviewing or motivational enhancement therapy (Miller \& Rollnick, 1991) is designed to alter behavior patterns that are substantially influenced by immediate contingencies, and to bring such behavior under the control of rules that highlight more distal consequences. When applied to substance abuse problems, for example, motivational interviewing includes treatment components that involve providing feedback to the client concerning current substance patterns and the likely longer-term effects associated with such use (e.g., as reflected by statements such as "if you continue to drink at your current level, it is very likely that you will experience a number or serious physical, social, and psychological problems in the future"). Such information about the detrimental long-term effects of alcohol use can make more salient connections between excessive alcohol consumption and more distal negative consequences as a means for bringing behavior under the influence of these consequences (via verbally-mediated rules). Subsequent phases of therapy involve the use of intervention strategies to capitalize on an established motivation for change by producing behavior patterns consistent with long term personal goals linked to change.

The identification and clarification of values, an examination of their compatibility with current behavior patterns, and establishing commitments to those goals are core features of other behaviorallyoriented therapies. In behavioral activation therapy (Martell, Addis, \& Jacobson, 2001), for example, an approach for shifting behaviors away from immediate contingencies to more distal outcomes is called "acting toward a goal." In acceptance and commitment therapy (Hayes, Strosahl, \& Wilson, 1999), a similar intervention strategy is called "committed action." Clients are encouraged to adopt behavior patterns that are consistent with how they would like to feel or how they would like to be perceived by themselves or others. In so doing, desirable distal consequences are made more salient, thus weakening the influence of more immediate contingencies on ongoing behavior.

\section{Impulsivity as an Indicator of Poor Inhibitory Controls}

Impulsive actions might signal problems in the inhibition of ongoing behavior (disinhibition), particularly in the presence of punishment cues for such behavior. Impulsivity, in some instances then, can be regarded as a problem with inhibitory control. Several prominent theories of attention deficit/hyperactivity disorder (ADHD), for example, conceptualize the disorder primarily in terms of an inhibition disorder (e.g., Barkley, 1997; Nigg, 2000). Within Gray's model, inhibition problems might be due, in part, to low anxiety or fear (BAS, FFFS). Finn, Mazas, Justus, and Steinmetz (2002), for example, found that persons low in harm avoidance (a construct similar to trait anxiety) demonstrated less reactivity to cues associated with shock punishment. Alternatively, impaired inhibition skills might be an acquired result of brain insult or injury, such as through chronic drug exposure (Bechara \& VanDer Linden, 2005; Dawe et al., 2004) or physical abuse and negle ct (Starling, Sirotnak, Heisler, \& BarnesEley, 2007).

In addition to interventions that facilitate awareness of behavior-consequence relations and likely distal outcomes associated with ongoing behavior, other potentially useful interventions might include those that increase the salience of cues to inhibit behavior. Stimulus control techniques have been used to effectively inhibit or reduce some behaviors. Wansink (2004), for example, provides several related suggestions for reducing food consumption through environmental manipulations. Such techniques might be used to not only reduce the influence that the sight of food might have on behavior, but to also increase the salience of more appropriate cues (e.g., internal physiological cues associated with hunger or fullness) as a means of regulating eating behavior.

Other possible interventions for impulsive actions associated with this response class include those that teach the skill of behavioral inhibition while the client is in the presence of cues that occasion disinhibited behavior. An example of one such intervention is cue exposure. This technique has been used to reduce drug cravings and the urge to use among those who abuse substances (Lee et al., 2004), and has 
used to reduce binge eating episodes among those with bulimia (Toro et al., 2003). When applied to alcohol abuse problems, this procedure involves the presentation of substance cues, such as the sights and smells of one's favorite beverage, without being followed by the consumption of the alcohol. During the exposure process, participants generally report that the urges, cravings, and emotions related to drinking subside. As such, this procedure is generally regarded as an extinction-based procedure. This procedure might also help develop behavioral inhibition skills, as the client is encouraged to fully experience events that are present prior to engagement in impulsive behavior, but to ultimately refrain from engaging in such behavior. As a result, tightly associated urge-action tendencies are weakened with repeated exposures and skills associated with the resisting of temptation are strengthened.

\section{Impulsivity as an Indicator of Impaired Attention Skills, Including Poor Stimulus Discrimination and Inappropriate Stimulus Control}

Various theorists have highlighted the role that impaired attentional skills or poor stimulus discrimination skills have in the commission of impulsive acts (Daruna \& Barnes 1993; Dickman, 1993, 2000). Inattention, although frequently included in self-report measures of impulsivity (e.g., Patton, Stanford, \& Barratt, 1995), appears to be more strongly associated with deficits in response inhibition (or behavioral disinhibition) than to trait impulsivity linked to appetitive behavior (Friedman \& Miyake, 2004). Consequently, interventions that attempt to augment inhibition control might have some utility in relation to this functional domain. Stimulus control techniques constitute one example of a group of interventions that might be useful for promoting behavioral inhibition. These techniques primarily involve the manipulation of antecedents of behavior and, in this instance, typically the removal of cues that reliably occasion the target behavior or the introduction of cues that signal to the individual to inhibit or moderate a particular behavior.

Relatedly, some clients who are inclined to act impulsively perhaps do so as a result of relatively poor stimulus discrimination skills. For individuals with such skills deficits, impulsive actions might signal inappropriate stimulus control, whereby behaviors that are appropriate in some contexts are sometimes displayed in situations where they are not appropriate. The resultant problem, then, might have more to do with difficulties in discriminating situations whereby the behavior is appropriate versus inappropriate, or difficulties in inhibiting inappropriate behaviors in the presence of situational cues that signal that such behavior is inappropriate in a particular context.

Mindfulness meditation practice has been incorporated into several behavior therapies, including those for anxiety disorders (Kabat-Zinn, et al., 1992), alcohol misuse (Witkiewitz, Marlatt, \& Walker, 2005), treatment resistant depression (Teasdale et al., 2000), and borderline personality disorder (Linehan, 1993a) among other conditions. In general, mindfulness mediation is used to assist the individual to develop an attentional focus on the present. Rumination and worry about the past or future is a feature of many emotional disorders, including depression, anxiety, or anger. A challenge of mindfulness practice is to pay attention, become aware and notice, to remain centered on the here and now, and to accept without choosing. Linehan (1993a) describes mindfulness as including observing experiences in the present moment, describing those experiences without judgments or evaluations, and participating fully in one's current context. Additionally, mindfulness involves being focused on one experience at a time, and responding effectively in relation to one's current experience or situation.

Self-labeling training is an example of an intervention that might be appropriate for persons who are inclined to act impulsively in the presence of negative emotional arousal that is not otherwise discriminated or differentiated. For a variety of reasons, some individuals have difficulty identifying and accurately labeling their emotional experiences, a phenomenon that has been labeled alexithymia. To strengthen the regulation of such emotional experiences, initial steps involve the identification and labeling of emotional experiences as well as events that trigger them (e.g., situations, thoughts). 
Additional therapeutic goals include linking emotions to behavioral inclinations or action urges, and the skill of accurately communicating one's emotional experiences to others (Linehan, 1993b).

\section{Impulsive Behavior as an Indicator of an Inability to Cope with Delay}

Impulsivity has sometimes been defined as the inability to pause or suspend actions or to defer consequences when doing so produces more optimal outcomes. Impulsivity, then, can be conceptualized as a type of choice behavior, whereby smaller immediate gains are selected over larger delayed gains, or larger delayed penalties are preferred over smaller immediate penalties (Logue, 1995). This tendency, sometimes referred to as delay discounting, has been frequently observed among persons who misuse substances (Kirby et al., 1999; Vuchinich \& Simpson, 1998).

One effective behavioral therapy approach to the treatment of substance abuse disorders attempts to weaken the influence of immediate reinforcement provided through substance use and to alter central characteristics of the drug abusing lifestyle by increasing the influence of healthier and non-drug sources of reinforcement. This multifaceted approach, called the Community Reinforcement plus Vouchers Approach, has been primarily been evaluated among cocaine dependent persons (Higgins, Heil, \& Sigmon, 2007). Therapists who work within the approach become actively involved in the promotion of substantial life change (e.g., by taking clients to job interviews). Therapists also facilitate the client's functional understanding of their substance use, and to use this information to take steps to reduce use (e.g., by coming up with solutions or plans to respond to the problems that substance use addresses, and to develop strategies for implementing these plans when substance use situations arise). Skill training might also be used (e.g., drug refusal skills). The voucher component is a contingency management based intervention whereby abstinence from substance use is reinforced. For each clean urine specimen, a voucher is issued, with the value of voucher incrementally increased with each successive clean specimen. The vouchers, in turn, can be redeemed for retail items in the community.

Other behavioral interventions that might be helpful for those who have difficulty with delay include self-management techniques. Examples of these strategies include stimulus control procedures, self-monitoring, goal setting, and behavioral contracting.

\section{SUMMARY}

Although centrally important to the definition of many forms of psychological disorder or maladjustment, the concept of impulsivity is not well-defined or understood. Findings from personality theory and research suggest that the behavioral manifestations of impulsivity are multifaceted, not well-captured by a single trait label, and likely arise from the interactions of several sources. Because of the emphasis on behavioral context over behavioral form, behavioral formulations of impulsive acts are in a unique position to account for the multifaceted nature of behaviors that fall within this general category, and to suggest intervention approaches strongly tied to the functional aspects of impulsive action.

\section{REFERENCES}

American Psychiatric Association (2000). Diagnostic and statistical manual of mental disorders (4th ed., text rev.). Washington, D.C.: Author.

Anderson, C.M., Hawkins, R.P., Freeman, K.A., \& Scotti, J.R. (2000). Private events: Do they belong in a science of human behavior? The Behavior Analyst, 23, 1-10.

Barkley, R.A. (1997). Behavioral inhibition, sustained attention, and executive functions: Constructing a unifying theory of ADHD. Psychological Bulletin, 121, 65-94. 
Barrett, E.S., \& Stanford, M.S. (1996). Impulsiveness. In C.G. Costello (Ed.), Personality characteristics of the personality disordered (pp. 91-119). New York: Wiley.

Bechara, A., \& Van Der Linden, M. (2005). Decision-making and impulse control after fontal lobe injuries. Current Opinion in Neurology, 18, 734-739.

Boyce, T.E., \& Roman, H.R. (2003). Contingency management interventions. In W. O'Donohue, J.E. Fisher, \& S.C. Hayes (Eds.), Cognitive behavior therapy: Applying empirically supported techniques in your practice (pp. 109-113). Hoboken, NJ: Wiley.

Brown, M.Z., Comtois, K.A., \& Linehan, M.M. (2002). Reasons for suicide attempts and nonsuicidal self-injury in women with borderline personality disorder. Journal of Abnormal Psychology, 111, 198-202.

Corr, P.J. (Ed.) (2008). The reinforcement sensitivity theory of personality. New York: Cambridge University Press.

Cloninger, C.R. (1987). A systematic method for clinical description and classification of personality variants: A proposal. Archives of General Psychiatry, 44, 573-588.

Costa, P.T., Jr., \& McCrae, R.R. (1992). Revised NEO Personality Inventory (NEO-PI-R) and NEO FiveFactor Inventory (NEO-FFI) professional manual. Odessa, FL: Psychological Assessment Resources.

Daruna, J.H., \& Barnes, P.A. (1993). A neurodevelopmental view of impulsivity. In W. G. McCown, J.L. Johnson, \& M.B. Shure (Eds.), The impulsive client: Theory, research, and treatment (pp. 23-37). Washington, DC: American Psychological Association.

Dawe, S., Gullo, M., \& Loxton, L.J. (2004). Reward drive and rash impulsiveness as dimensions of impulsivity: Implications for substance misuse. Addictive Behaviors, 29, 1389-1406.

Depue, R.A., \& Collins, P.F. (1999). Neurobiology of the structure of personality: Dopamine, facilitation of incentive motivation, and extraversion. Behavioural and Brain Sciences, 22, 491-569.

Dickman, S.J. (1990). Functional and dysfunctional impulsivity: Personality and cognitive correlates. Journal of Personality and Social Psychology, 58, 95-102.

Dickman, S.J. (1993). Impulsivity and information processing. In W.G. McCown, J.L. Johnson, \& M.B. Shure (Eds.), The impulsive client: Theory, research, and treatment (pp. 151-184). Washington, DC: American Psychological Association.

Dickman, S.J. (2000). Impulsivity, arousal and attention. Personality and Individual Differences, 28, 563581.

Dickman, S.J., \& Meyer, D.E. (1988). Impulsivity and speed-accuracy tradeoffs in information processing. Journal of Personality and Social Psychology, 54, 274-290.

Disney, E.R., Elkins, I.J., McGue, M., \& Iacono, W.G. (1999). Effects of ADHD, conduct disorder, and gender on substance use and abuse in adolescents. American Journal of Psychiatry, 156, 15151521.

Evenden, J.L. (1999). Varieties of impulsivity. Psychopharmacology, 146, 348-361. 
Farmer, R.F., \& Chapman, A.L. (2008). Behavioral interventions in cognitive behavior therapy: Practical guidance for putting theory into action. Washington, DC: American Psychological Association.

Farmer, R.F., Field, C.E., Gremore, T.M., Chapman, A.L., Nash, H.M., \& Mayer, J.L. (2003). Passive avoidance learning among females as a function of Cloninger's temperament typology. Personality and Individual Differences, 34, 983-997.

Farmer, R.F., \& Nelson-Gray, R.O. (2005). Personality-guided behavior therapy. Washington, DC: American Psychological Association.

Farmer, R.F., \& Rucklidge, J.J. (2006). An evaluation of the response modulation hypothesis in relation to attention-deficit/hyperactivity disorder. Journal of Abnormal Child Psychology, 34, 545-557.

Farmer, R.F., Seeley, J.R., Kosty, D.B., \& Lewinsohn, P.M. (in press). Refinements of the hierarchical structure of externalizing psychiatric disorders: Patterns of lifetime liability from midadolescence through early adulthood. Journal of Abnormal Psychology.

Farmer, R.F., Whitehead, K.A., \& Woolcock, C.M. (2007). Temperament, executive functions, and the allocation of attention to punishment feedback in passive avoidance learning. Journal of Personality. 75, 569-593.

Finn, P.R., Mazas, C.A., Justus, A.N., \& Steinmetz, J. (2002). Early-onset alcoholism with conduct disorder: Go/no go learning deficits, working memory capacity and personality. Alcoholism: Clinical and Experimental Research, 26, 186-206.

Foa, E. B., \& Kozak, M. J. (1986). Emotional processing of fear: Exposure to corrective information. Psychological Bulletin, 99, 20-35.

Follette, W.C., Naugle, A.E., Linnerooth, P.J.N. (2000). Functional alternatives to traditional assessment and diagnosis. In M.J. Dougher (Ed.), Clinical behavior analysis (pp. 99-125). Reno, NV: Context Press.

Fowles, D.C. (1980). The three arousal model: Implications of Gray's two-factor learning theory for heart rate, electrodermal activity, and psychopathy. Psychophysiology, 17, 87-104.

Friedman, N.P., \& Miyake, A. (2004). The relations among inhibition and interference control functions: A latent-variable analysis. Journal of Experimental Psychology: General, 133, 101-135.

Goldberg, L.R. (1990). An alternative "description of personality": The Big-Five factor structure. Journal of Personality and Social Psychology, 59, 1216-1229.

Goldberg, L.R. (1992). The development of markers for the big-five factor structure. Psychological Assessment, 4, 26-42.

Gray, J.A. (1973). Causal theories of personality and how to test them. In J. R. Royce (Ed.), Multivariate analysis and psychological theory (pp. 409-451). New York: Academic Press.

Gray, J.A. (1987). The psychology offear and stress (2nd ed.). New York: Cambridge University Press.

Gray, J.A., \& McNaughton, N. (2000). The neuropsychology of anxiety ( $2^{\text {nd }}$ ed.) London: Oxford University Press.

Hayes, S.C., Strosahl, K.D., \& Wilson, K.G. (1999). Acceptance and commitment therapy: An experiential approach to behavior change. New York: Guilford. 
Hayes, S.C., Wilson, K.G., Gifford, E.V., Follette, V.M., \& Strosahl, K. (1996). Experiential avoidance and behavioral disorders: A functional dimensional approach to diagnosis and treatment. Journal of Consulting and Clinical Psychology, 64, 1152-1168.

Higgins, S.T., Heil, S.H., \& Sigmon, S.C. (2007). A behavioral approach to the treatment of substance abuse disorders. In P. Sturmey (Ed.), Functional analysis in clinical treatment (pp. 261-282). Boston, MA: Academic Press.

Kabat-Zinn, J., Massion, A.O., Kristeller, J., Peterson, L.G., Fletcher, K., Pbert, L., et al. (1992). Effectiveness of a meditation-based stress reduction program in the treatment of anxiety disorders. American Journal of Psychiatry, 149, 936-943.

Kearney, A.J. (2006). A primer of covert sensitization. Cognitive and Behavioral Practice, 13, 167-175.

Kelso, P., Miltenberger, R., Watres, M. Emgemo-Helm, K., \& Bagne, A. (2007). Teaching skills to second and third grade children to prevent gun play: A comparison of procedures. Education and Treatment of Children, 30, 29-48.

Kirby, K.N., Petry, N.M., \& Bickel, W.K. (1999). Heroin addicts have higher discount rates for delayed rewards than non-drug using controls. Journal of Experimental Psychology: General, 128, 78-87.

Klonsky, E.D., \& Olino, T.M. (2008). Identifying clinically distinct subgroups of self-injurers among young adults: A latent class analysis. Journal of Consulting and Clinical Psychology, 76, 22-27.

Krueger, R.F. (1999). The structure of common mental disorders. Archives of General Psychiatry, 56, 921-926.

Lee, J., Lim, Y., Graham, S.J., Kim, G., Wiederhold, B.K., Wiederhold, M.D., et al. (2004). Nicotine craving and cue exposure therapy by using virtual environments. CyberPsychology \& Behavior, 7, 705-713.

Linehan, M.M. (1993a). Cognitive-behavioral treatment of borderline personality disorder. New York: Guilford.

Linehan, M.M. (1993b). Skills training manual for treating borderline personality disorder. New York: Guilford.

Linehan, M. M., Armstrong, H.E., Suarez, A., Allmon, D., \& Heard, H.L. (1991). Cognitive-behavioral treatment of chronically parasuicidal borderline patients. Archives of General Psychiatry, 48, 1060-1064.

Linehan, M. M., Comtois, K. A., Murray, A. M., Brown, M. Z., Gallop, R. J., Heard, H. L., et al. (2006). Two-year randomized controlled trial and follow-up of dialectical behavior therapy vs. therapy by experts for suicidal behaviors and borderline personality disorder. Archives of General Psychiatry, 63, 757-766.

Lloyd, A. (2003). Urge surfing. In W. O’Donohue, J.E. Fisher, \& S.C. Hayes (Eds.), Cognitive behavior therapy: Applying empirically supported techniques in your practice (pp. 451-455). Hoboken, NJ: Wiley.

Logue, A.W. (1995). Self-control: Waiting until tomorrow for what you want today. Englewood Cliffs, NJ: Prentice Hall. 
Lykken, D.T. (1957). A study of anxiety in the sociopathic personality. Journal of Abnormal and Social Psychology, 55, 6-10.

Lykken, D.T. (1995). The antisocial personalities. Hillsdale, NJ: Erlbaum.

Malott, R.W. (1989). The achievement of evasive goals: Control by rules describing contingencies that are not direct acting. In S.C. Hayes (Ed.) Rule governed behavior: Cognition, contingencies, and instructional control (pp. 269-322). New York: Plenum Press.

Malott, R.W., Malott, M.E., \& Trojan, E.A. (2000). Elementary principles of behavior $\left(4^{\text {th }}\right.$ ed.). Upper Saddle River, NJ: Prentice-Hall.

Marlatt, G.A., \& Gordon, J.R. (Eds.) (1985). Relapse prevention: Maintenance strategies in the treatment of addictive behaviors. New York: Guilford.

Martell, C.R., Addis, M.E., \& Jacobson, N.S. (2001). Depression in context: Strategies for guided action . New York: Norton.

McCrae, R.R. (2004). Human nature and culture: A trait perspective. Journal of Research in Personality, $38,3-14$.

Michael, J. (1982). Distinguishing between the discriminative and motivational functions of stimuli. Journal of the Experimental Analysis of Behavior, 37, 149-158.

Miller, W.R., \& Rollnick, S. (1991). Motivational interviewing: Preparing people to change addictive behavior. New York: Guilford.

Miltenberger, R.G. (2005). The role of automatic negative reinforcement in clinical problems. International Journal of Behavioral Consultation and Therapy, 1, 1-11.

Miltenberger, R. (2009). Evaluating behavioral skills training with and without simulated in situ train ing for teaching safety skills to children. Education and Treatment of Children, 32, 64-73.

Moeller, F.G., Barratt, E.S., Dougherty, D.M., Schmitz, J.M., \& Swann, A.C. (2001). Psychiatric aspects of impulsivity. American Journal of Psychiatry, 158, 1783-1793.

Muehlenkamp, J.J. (2006). Empirically supported treatments and general therapy guidelines for nonsuicidal self-injury. Journal of Mental Health Counseling, 28, 166-185.

Nelson-Gray, R.O., \& Farmer, R.F. (1999). Behavioral assessment of personality disorders. Behaviour Research and Therapy, 37, 347-368.

Nemeroff, C.B., Bremner, J.D., Foa, E.B., Mayberg, H.S., North, C.S., \& Stein, M.B. (2005).

Posttraumatic stress disorder: A state-of-the-science review. Journal of Psychiatric Research, 40, $1-21$.

Newman, J.P. (1987). Reaction to punishment in extraverts and psychopaths: Implications for the impulsive behavior of disinhibited individuals. Journal of Research in Personality, 21, 464-480.

Ninness, H.A.C., Fuerst, J., Rutherford, R.D., \& Glenn, S.S. (1991). Effects of self-management training and reinforcement on the transfer of improved conduct in the absence of improved conduct in the absence of supervision. Journal of Applied Behavior Analysis, 24, 499-508. 
Nigg, J.T. (2000). On inhibition/disinhibition in developmental psychopathology: Views from cognitive and personality psychology and a working inhibition taxonomy. Psychological Bulletin, 126, 200246.

Patterson, C.M., \& Newman, J.P. (1993). Reflectivity and learning from aversive events: Towards a psychological mechanism for the syndromes of disinhibition. Psychological Review, 100, 716736.

Patterson, G.R., \& Hops, H. (1972). Coercion, a game for two: Intervention techniques for marital conflict. In R. Ulrich and P. Mountjoy (Eds.), The experimental analysis of social behavior (pp. 424-440). New York: Appleton-Century-Crofts.

Patton, J. H., Stanford, M. S., Barratt, E.S. (1995). Factor structure of the Barratt Impulsiveness Scale. Journal of Clinical Psychology, 51, 768-774.

Poling, A., \& Gaynor, S.T. (2003). Stimulus control. In W. O’Donohue, J. E. Fisher, \& S. C. Hayes (Eds.), Cognitive behavior therapy: Applying empirically supported techniques in your practice (pp. 396-401). Hoboken, NJ: Wiley.

Redlin, J.A., Miltenberger, R.G., Crosby, R.D., Wolff, G.E., \& Stickney, M.I. (2002). Functional assessment of binge eating in a clinical sample of obese eaters. Eating and Weight Disorders, 7 , 106-115.

Scotti, J.R., Morris, T.L., McNeil, C.B., \& Hawkins, R.P. (1996). DSM-IV and disorders of childhood and adolescence: Can structural criteria be functional? Journal of Consulting and Clinical Psychology, 64, 1177-1191.

Smillie, L.D., Pickering, A.D., \& Jackson, C.J. (2006). The new reinforcement sensitivity theory: Implications for personality measurement. Personality and Social Psychology Review, 10, 320335 .

Smillie, L.D., \& Jackson, C.J. (2006). Functional impulsivity and reinforcement sensitivity theory. Journal of Personality, 74, 47-83.

Spielberger, C.D., \& DeNike, L. D. (1966). Descriptive behaviorism versus cognitive theory in verbal operant conditioning. Psychological Review, 73, 306-326.

Starling, S.P., Sirotnak, A.P., Heisler, K.W., \& Barnes-Eley, M.L. (2007). Inflicted skeletal trauma: The relationship of perpetrators to their victims. Child Abuse and Neglect, 31, 993-999.

Stickney, M.I., \& Miltenberger, R.G. (1999). Evaluating direct and indirect measures for the functional assessment of binge eating. International Journal of Eating Disorders, 26,195-204.

Teasdale, J. D., Segal, Z. V., Williams, J. M. G., Ridgeway, V. A., Soulsby, J. M., \& Lau, M. A. (2000). Prevention of relapse/recurrence in major depression by mindfulness-based cognitive therapy. Journal of Consulting and Clinical Psychology, 68, 615-623.

Tellegen, A. (1999). MPQ (Multidimensional Personality Questionnaire): Manual for administration, scoring, and interpretation. Minneapolis, MN: University of Minnesota Press.

Toro, J., Cervera, M., Feliu, M.H., Garriga, N., Jou, M., Martinez, E., et al. (2003). Cue exposure in the treatment of resistant bulimia nervosa. International Journal of Eating Disorders, 34, 227-234. 
Vuchinich, R.E., \& Simpson, C.A. (1998). Hyperbolic temporal discouting in social drinkers and problem drinkers. Experimental and Clinical Psychopharmacology, 5, 256-262.

Wallace, J., Bachorowski, J., \& Newman, J.P. (1991). Failures of response modulation: Impulsive behavior in anxious and impulsive individuals. Journal of Research in Personality, 25, 23-44.

Wansink, B. (2004). Environmental factors that increase the food intake and consumption volume of unknowing consumers. Annual Review of Nutrition, 24, 455-479.

Whiteside, S.P., \& Lynam, D.R. (2001). The Five Factor Model and impulsivity: Using a structural model of personality to understand impulsivity. Personality and Individual Differences, 30, 669-689.

Witkiewitz, K., Marlatt, G. A., \& Walker, D. (2005). Mindfulness-based relapse prevention for alcohol and substance use disorders. Journal of Cognitive Psychotherapy, 19, 211-228.

Young, S.E., Friedman, N.P., Miyake, A., Willcutt, E.G., Corley, R.P., Haberstick, B.C., et al. (2009). Behavioral disinhibition: Liability for externalizing spectrum disorders and its genetic and environmental relation to response inhibition across adolescence. Journal of Abnormal Psychology, 118, 117-130.

Zuckerman, M. (1996). Sensation seeking. In C.G. Costello (Ed.), Personality characteristics of the personality disordered (pp. 289-316). New York: Wiley.

Contact Information:

Richard Farmer, Ph.D.

Department of Psychology

Rawl Building

East Carolina University

Greenville, North Carolina 27858

farmerr@ecu.edu

\author{
Jeannie Golden, Ph.D. \\ Department of Psychology \\ Rawl Building \\ East Carolina University \\ Greenville, North Carolina 27858 \\ goldenj@ecu.edu
}

